\title{
Molecular Blood Group Diagnostics
}

\author{
Christoph Gassner \\ Central Institute for Blood Transfusion and Immunological Department, Innsbruck, Austria
}

This and the next issue of Transfusion Medicine and HemoTHERAPY draw special attention to 'Molecular Blood Group Diagnostics' and 'Molecular Diagnostics in the Whole Genome Age', respectively.

Scientific reports related on molecular blood group diagnostics by scientists from German speaking countries are significant measured by impact and numbers. However, this special issue of Transfusion Medicine and Hemotherapy will refrain from focusing on 'historical' findings and rather address timely topics: This issue reviews on different methods for medium- to high-throughput DNA typing methods, precises currently debated routine applications for blood group genotyping, and puts the question: 'Will genotyping replace serology in future routine blood grouping?'

Looking back for the last two decades, DNA typing in molecular blood group diagnostics widely took benefit from technologies established and tested for HLA typing in the first place. Still, peering over the 'HLA shoulder' results in interesting technology transfers as illustrated in this issue for the Luminex ${ }^{\circledR}$ methodology by Drago et al. [1]. On the other hand, there are different specifications in blood group genotyping with respect to sample numbers and gene polymorphism as compared to HLA. This might explain, why chip-based DNA typing is adopted sincerely by blood group specialists, as being detailed in two contributions by Avent et al. [2] and Reid [3] in the current issue. The key aspect of methods for medium- to high-throughput DNA typing methods is rounded up by a review report on MALDI-TOF mass spectrometry and its fascinating potential for blood group DNA typing by Garritsen et al. [4].

Today, employment of molecular blood group diagnostics for the genetically exact definition of blood group variants (e.g. $R H D$ and $A B O$ ), clarification of original genotypes in polytransfused sample material, or antibody-masked erythrocytes are generally accepted. However, there are other attractive applications of this methodology, e.g. in testing a fetus' $R H D$ type from maternal serum. Referring to this, Legler et al. [5] present a timely review of current European efforts. Cost-effective screening for donors with rare antigen profiles represents another up-to-date topic and is picked out twice as a central one in this issue by Jungbauer [6] and Wagner [7]. Since nobody can do without quality control nowadays, an example of how molecular blood group diagnostics might influence serological validation processes is presented by Gassner et al. [8]. No matter which method is being used and blood group polymorphisms are being analysed, there will always be a certain percentage of samples remaining inconclusive when combining serological and molecular biological results. In most cases, these results will present new blood group alleles, and there is a vital interest for resolving these cases by means of DNA sequence-based typing as being detailed by Seltsam and Doescher [9].

Five expert opinions on the question 'Will genotyping replace serology routine blood grouping in the future?' represent a third key aspect of this issue [10-14]. Experts are being challenged by giving editorial sub-queries such as: 'Should there be genotyping for 'all' (currently available) blood groups of all donors? Could there be additional testing for genetic markers encoding 'soft' genetic diseases such as e.g. haemochromatosis, hereby extending responsibility range of blood typing centres in the context of public health? Could there be a blood group serologists' approval for 'in silico' cross-matching, given all available blood groups of each transfusion event were genetically determined?'

Browsing the content of this issue, most of the technical applications which are being presented are developed and tested in highly specialised laboratories only. Some of them will always remain there. Others will might be picked up by the industry and made accessible to the end users. In any case, skilled experts in molecular biology and intense cross-talk to medical specialists are two irreplaceable prerequisites for an innovative application of modern molecular blood group diagnostics.

\section{KARGER}

Fax +497614520714

Information@Karger.de

www.karger.com (c) 2009 S. Karger GmbH, Freiburg

Accessible online at:

www.karger.com/tmh
Dr. Christoph Gassner

Zentralinstitut für Bluttransfusion und Immunologische Abteilung

Anichstraße 35, 6020 Innsbruck, Austria

christoph.gassner@uki.at 


\section{References}

1 Drago F, Karpasitou K, Poli F: Microarray beads for identifying blood group single nucleotide polymorphisms. Transfus Med Hemother 2009;36(3): 157-160.

2 Avent ND, Martinez A, Flegel WA, Olsson ML, Scott ML, Nogués N, Písačka M, Daniels GF, Muñiz-Diaz E, Madgett TE, Storry JR, Beiboer S, Maaskant-van Wijk PM, von Zabern I, Jiménez E, Tejedor D, López M, Camacho E, Cheroutre G Hacker A, Jinoch P, Svobodova I, van der Schoot E, de Haas M. The Bloodgen project of the European Union, 2003-2009. Transfus Med Hemother 2009;36(3):162-167.

3 Reid ME: Applications and experience with PCR based assays to predict blood group antigens Transfus Med Hemother 2009;36(3):168-178.

4 Garritsen HSP, Fan A, Lenz D, Hannig H, Zhong XY, Geffers R, Lindenmaier W, Dittmar KEJ, Wörmann B: Molecular diagnostics in transfusion medicine: in capillary, on a chip, in silico or in flight? Transfus Med Hemother 2009;36(3):181-187.
5 Legler TJ, Müller SP, Haverkamp A, Grill S, Hahn $\mathrm{S}$ : Prenatal RhD testing: a review of studies published from 2006 to 2008. Transfus Med Hemother 2009;36(3):189-198.

6 Jungbauer C: Molecular bases and genotyping for rare blood types. Transfus Med Hemother 2009; 36(3):213-218.

7 Wagner F: Screening donors for rare antigen constellations. Transfus Med Hemother 2009;36(3): 199-203.

8 Seltsam A, Doescher A: Sequence-based typing of human blood groups. Transfus Med Hemother 2009;36(3):204-212.

9 Gassner C, Rainer E, Pircher E, Markut L, Körmöczi GF, Jungbauer C, Wessin D, Klinghofer R, Schennach H, Schwind P, Schönitzer D: Application of a multi-variant, Caucasian-specific, genotyped donor panel for performance validation of MDmulticard ${ }^{\circledR}$, ID-System ${ }^{\circledR}$, and Scangel ${ }^{\circledR}$ $\mathrm{RhD} / \mathrm{ABO}$ serotyping. Transfus Med Hemother 2009;36(3):219-225.
10 Wagner FF: Will genotyping replace serology in future routine blood gouping? - opinion 1. Transfus Med Hemother 2009;36(3):226-227.

11 Hustinx H, Fontana S, Gowland P, Niederhauser $\mathrm{C}$ : Will genotyping replace serology in future routine blood grouping? - opinion 2. Transfus Med Hemother 2009;36(3):228-229.

12 Schönitzer D: Will genotyping replace serology in future routine blood grouping? - opinion 3. Transfus Med Hemother 2009;36(3):230-231.

13 Storry JR, Olsson ML: Will genotyping replace serology in future routine blood grouping? - opinion 4. Personalized versus universal blood transfusions - combining the efforts. Transfus Med Hemother 2009;36(3):232-233

14 van der Schoot CE, Veldhuisen B, de Haas M: Will genotyping replace serology in future routine blood grouping? - opinion 5. Transfus Med Hemother 2009;36(3):234-235 